\title{
Sonerila konkanensis (Melastomataceae), a new species from South Goa, India
}

\author{
Sekarathil Resmi, Santhosh Nampy \& Pracy Fernandes Akshatra
}

\begin{abstract}
RESMI, S., S. NAMPY \& P.F. AKSHATRA (2021). Sonerila konkanensis (Melastomataceae), a new species from South Goa, India. Candollea 76: 139-143. In English, English abstract. DOI: http://dx.doi.org/10.15553/c2021v761a14

A new tuberous species of Sonerila Roxb. (Melastomataceae, Sonerileae) from Chandreshwar hills, South Goa is described in the course of a taxonomic revision of the genus in India. Sonerila konkanensis Resmi \& Nampy is similar to Sonerila talbotii G.S. Giri \& M.P. Nayar and Sonerila sreenarayaniana Sunil et al. but differs in several characters that are detailed in the morphological discussion presented herein. The status of the new taxon is assessed as "Vulnerable" according to IUCN Red List Categories and Criteria. We also provide explanatory images of living plants as well as SEM images of pollen grains and seeds and information concerning the habitat.
\end{abstract}

\section{Keywords}

MELASTOMATACEAE - Sonerila - South India - Goa - New species

\footnotetext{
Addresses of the authors:

SR, SN: Department of Botany, University of Calicut, Malappuram District, Kerala 673 635, India.

E-mail: santhoshnampy2019@gmail.com

PFA: Department of Botany, Goa University, Taleigao Plateau, Goa 403 206, India.
}

Submitted on August 29, 2020. Accepted on March 15, 2021.

First published online on May 20,2021.

ISSN : 0373-2967 - Online ISSN : 2235-3658 - Candollea 76(1):139-143 (2021) 


\section{Introduction}

Sonerila Roxb. is an Old World genus of the family Melastomataceae (tribe Sonerileae) comprising around 180 taxa and distributed in the Indo-Pacific regions (CELlinese, 1997; Resmi et al., 2018). It is the largest genus of the tribe Sonerileae in India with about 62 species having a sizeable percentage $(83 \%)$ of endemism. A proportionally high number of species have been described during the last ten years from the Western Ghats, which is considered one of the major centres of diversity for the genus with 53 species and two varieties. The genus includes caulescent/acaulescent herbs thriving in shady habitats, sometimes bearing tubers. After vegetative growth and flowering, the tubers undergo a period of dormancy within the humus-rich rock crevices, but with the retreat of monsoon develop into new shoots. The plants are usually herbaceous or suffrutescent woody herbs with simple or branched stems. Stems and branches are terete to quadrangular and glabrous to hairy (Lundin, 1983). The most remarkable features of the genus are the generally trimerous flowers, arranged in mostly uniparous (scorpioid) cymes, and the 3-locular, inferior ovary.

The authors have been collecting Sonerila since 2015 in the course of a taxonomic revision of the genus in India. During field surveys to Chandreshwar hills of Salcete taluk in South Goa, we found a tuberous, caulescent representative of Sonerila that could not be ascribed to any known species. We therefore formally describe the new species $S$. konkanensis Resmi \& Nampy. A detailed morphological description, diagnostic characters, distribution data and a preliminary conservation status assessment are provided.

\section{Materials and Methods}

Relevant taxonomic accounts (TrianA, 1871; CLARKE, 1879; Cogniaux, 1891; StapF, 1892; Lundin, 1983; Giri \& Nayar, 1986; Sunil et al., 2014), herbarium specimens (CALI, MH, TBGT, CAL), and web-based herbarium resources available from BM, E, G, K and P were revised for discriminating purposes. The terminology proposed by STEARN (1992) and Giri \& Nayar (1986) was adopted to describe the SEM aspects of the seed coat. Photographs were taken with an EZ 4HD stereo microscope with a 3.0 Mega Pixel Digital camera (Leica, Switzerland) and Stemi 508 stereo microscope (Zeiss, Germany) attached with an Axiocam 105 colour camera. Pollen descriptions were made following Patel et al. (1984) and Chantaranothai (1997). Material of living plants was maintained in the Calicut University Botanical Garden (CUBG) to observe variation under cultivation.

\section{Taxonomy}

Sonerila konkanensis Resmi \& Nampy, sp. nov. (Fig. 1-2).

Holotypus: India. Goa: South Goa Dist., Salcete taluk, Mulem, Chandreshwar hills, on the way to Chandreshwar temple, Ghat road cuttings, $15^{\circ} 13^{\prime} 16^{\prime \prime N} 74^{\circ} 01^{\prime} 59^{\prime \prime} \mathrm{E}$, c. 220 m, 3.IX.2019, fl. \& fr., Resmi \& Akshatra 164408 (CALI!; iso-: G!, MH!).

Sonerila konkanensis Resmi $\Xi$ Nampy differs from S. talbotii G.S. Giri \& M.P. Nayar in petiole length (2-3.5 vs. 1-2 cm long), lamina shape (ovate to elliptic vs. elliptic to lanceolate), peduncle length (4-7 vs. 3-5 cm), flower number (6-20 vs. 3-12 per cyme), bract shape (ovate to elliptic vs. subulate) and petal shape (ovate to oblong vs. elliptic to oblong). The new species differs from S. sreenarayaniana Sunil et al. in root stock type (tuberous vs. non-tuberous), peduncle length (4-7 vs. 8-13 cm), bracts (persistent vs. apparently absent) and petals shape (ovate to oblong vs. ovate-obovate).

Herbs perennial, erect, caulescent, 5-30 cm tall. Root stocks tuberous; tubers globose, $0.5-1.5 \mathrm{~cm}$ diam., white to pale green with tufts of roots all over. Stems angular with prominent leaf scars on nodes, sub-angular at the base, $0.2-0.6 \mathrm{~cm}$ thick, green with a claret tinge, fleshy, corners distinctly marked with a dark pink colour, simple or branched; internodes $2-5 \mathrm{~cm}$ long, densely hairy at nodes. Stems, branches, petioles, laminae, bracts, peduncles, pedicels and hypanthia covered with dense glandular trichomes (trichomes $<2.5 \mathrm{~mm}$ long). Leaves simple, decussate, sometimes clustered at the distal nodes; petioles adaxially grooved or canaliculate, $2-3.5 \times 0.2-0.27 \mathrm{~cm}$, green with a claret tinge towards apex; laminae ovate to elliptic, $3-8 \times 1.5-4 \mathrm{~cm}$, lime green adaxially, pale green abaxially, cordate or sub-rounded at base with non-overlapping margins, acute to acuminate at apex, densely glandular-hairy adaxially but only on midrib and lateral veins abaxially, margins serrate to dentate with each tooth ending in a terminal glandular trichome; veins pinnate, 2 pairs from the base and 2 to 3 pairs from midrib above, less branched, impressed adaxially, conspicuous abaxially. Inflorescences scorpioid cymose, terminal, unbranched, usually 1 to 2 cymes arising from the distal node of the stem and branches (sometimes 3 to 5), 6 to 20-flowered; peduncles angular, $4-7 \times 0.15-0.25 \mathrm{~cm}$, longer than petioles; bracts leaf-like, ovate to elliptic, $0.5-2.5 \times 0.5-1.5 \mathrm{~cm}$, persistent. Flowers trimerous, rarely tetramerous, $1-1.6 \times 1-1.5 \mathrm{~cm}$; pedicels sub-angular, 4-10 $\times 1-1.8 \mathrm{~mm}$, longer in fruit, claret coloured. Hypanthia campanulate, 4-5 × 1.5-2.7 mm, 3-lobed, obscurely 3 -ribbed, green with a claret tinge towards apex; lobes triangular, $1-2 \times 1-2 \mathrm{~mm}$, acute at apex. Petals 3 , ovate to oblong, $8-12 \times 4-5 \mathrm{~mm}$, pale pink with a darker midrib, obtuse at base, mucronate at apex, glabrous adaxially, with glandular trichomes on midrib abaxially. Stamens 3, alternate to petals; filaments 5-6 mm long, dark pink, pale towards apex, glabrous, 

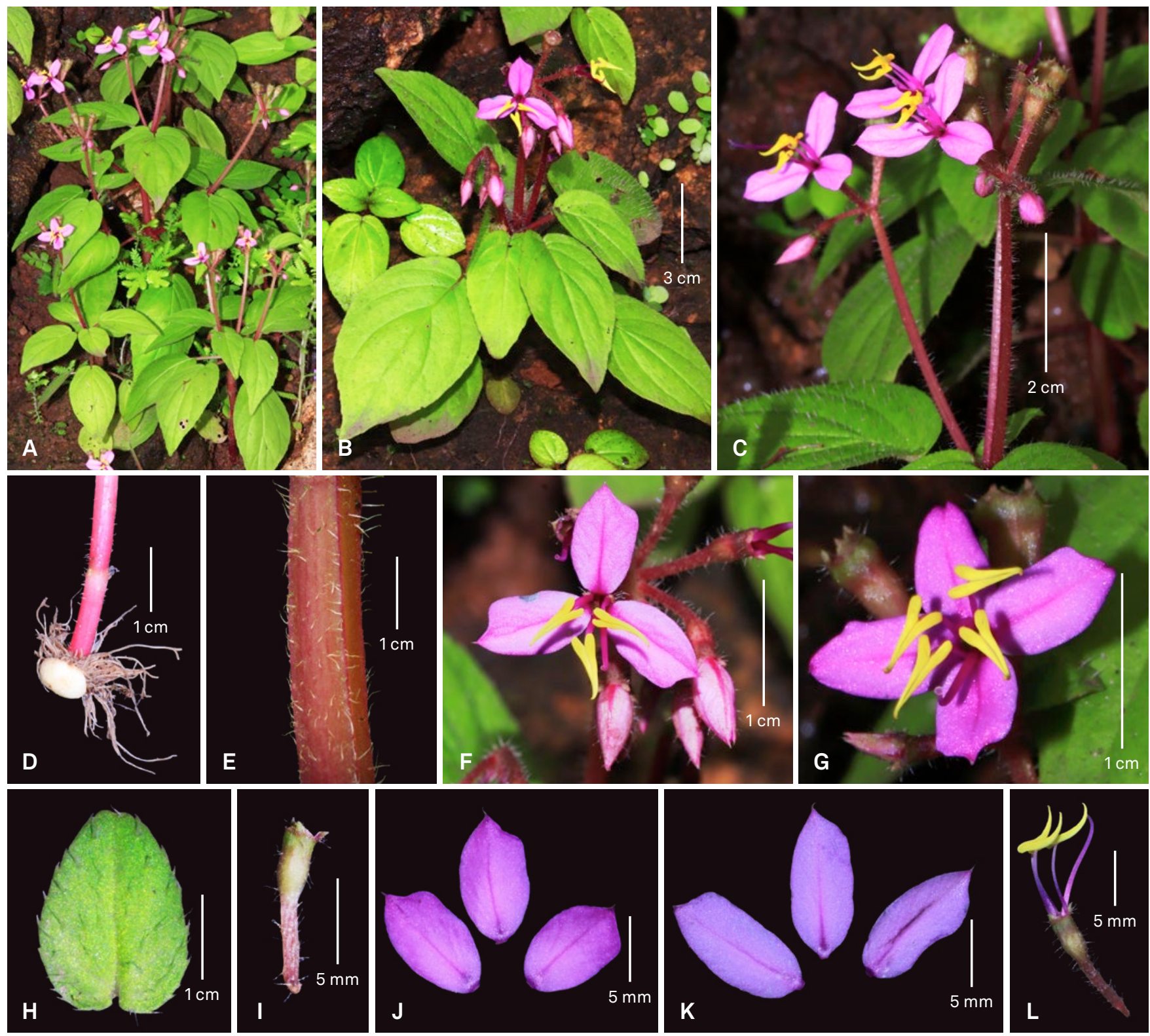

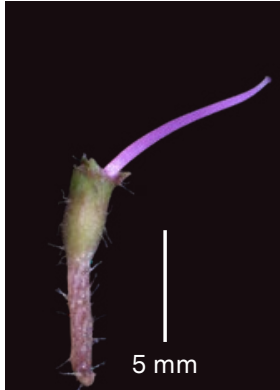

M
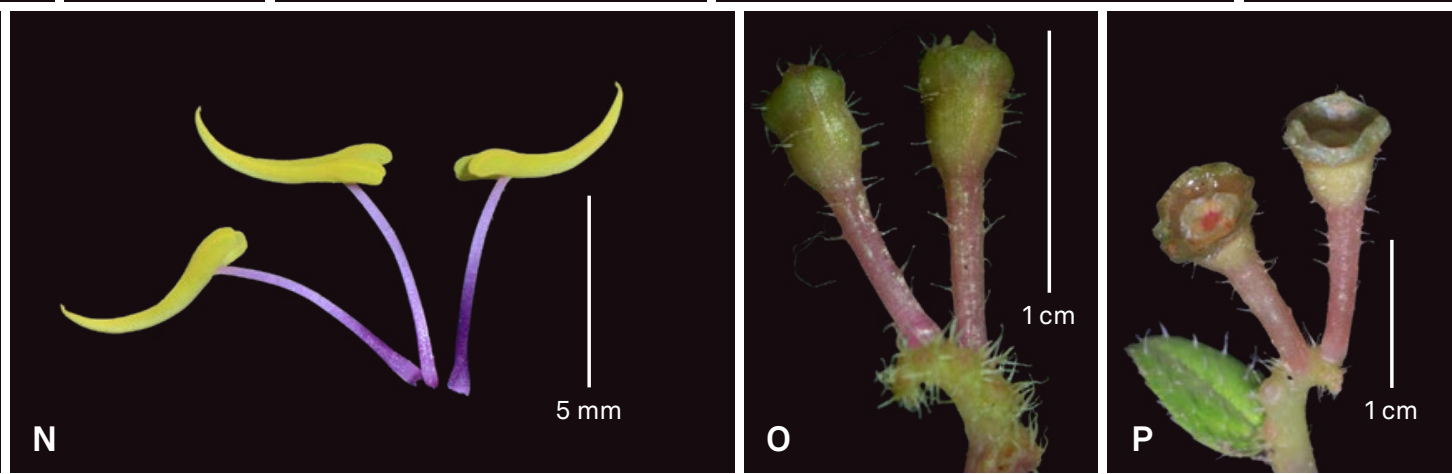

Fig. 1. - Sonerila konkanensis Resmi \& Nampy. A-B. Plants in their natural habitat (see tetramerous flower within the same population); C. Cymes; D. Stem base showing tuberous root stock; E. Angular stem; F. Inflorescence; G. Tetramerous flower; H. Bract, adaxial view; I. Hypanthium;

J. Ovate petals, adaxial view; K. Oblong petals, adaxial view; L. Hypanthium with stamens and pistil; M. Pistil; N. Stamens; O. Immature capsules;

P. Mature capsules and a persistent bract. [Resmi \& Akshatra 164408, CALI] [Photos: S. Resmi]. 

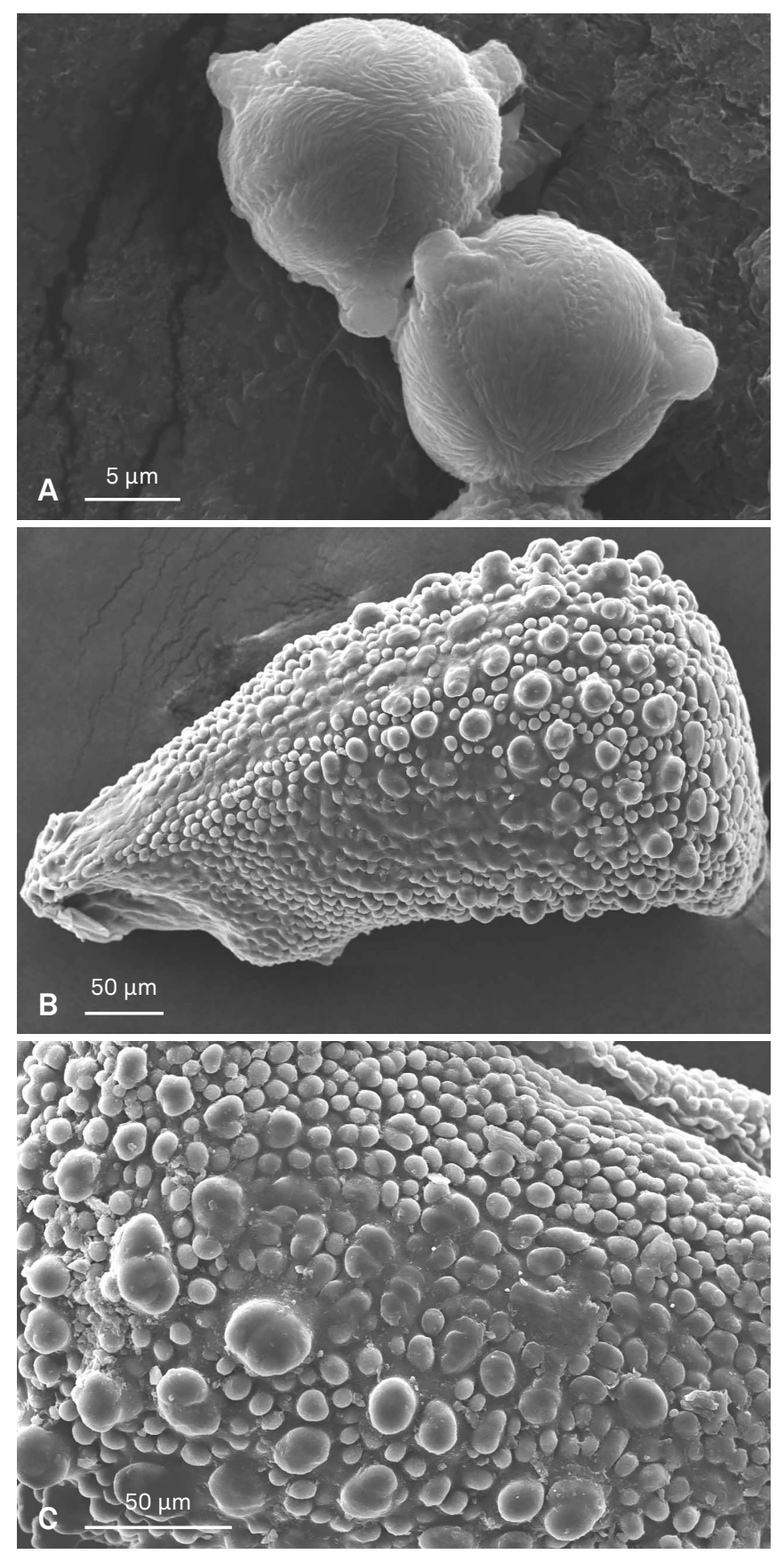

Fig. 2. - SEM images of Sonerila konkanensis Resmi \& Nampy. A. Pollen grains; B-C. Seed.

dilated and twisted downwards; anthers sagittate to deeply cordate at base, 5-6 $\mathrm{mm}$ long, yellow, acuminate to rostrate at apex, dehiscing through apical pores. Pollen grain 3-zonocolporate, oblate-spheroidal, striate with sculpturing parallel to the apertures and subsidiary colpi. Ovaries inferior, united with the hypanthium by half of its length, $2-2.5 \times 2-3 \mathrm{~mm}$; styles filiform, $8-10 \mathrm{~mm}$ long, dark pink, equal or shorter than stamens; stigmas capitate, pink, rugose, glabrous. Capsules urceolate,
4-5 $\times 4-5 \mathrm{~mm}$, green with a claret tinge, obscurely 3-ribbed, densely glandular pubescent, many seeded. Seeds obovoid, $0.4-0.5 \times 0.2-0.25 \mathrm{~mm}$, pale brown; raphes not prominent; testae sparsely tuberculate at dorsal angle and densely pusticulate throughout; tubercles with broad base and head, not covered with pusticles, with somewhat smooth surface.

Etymology. - The specific epithet refers to the type locality, which lies within the region of iconic biodiversity called "Konkan".

Distribution, habitat and phenology. - Known only from the type locality, Chandreshwar hills in South Goa district. It grows in wet humus and on damp rocks along the Ghat road cuttings, between elevations of $210-280 \mathrm{~m}$. Plants usually perennate by dormant tubers. It is found in association with Adiantum lunulatum Burm. f. (Adiantaceae), Arachniodes aristata (G. Forst) Tindale (Dryopteridaceae), Athyrium sp. (Athyriaceae), Begonia integrifolia Dalzell. (Begoniaceae), Cheilanthes sp. (Pteridaceae), Exacum petiolare Griseb. (Gentianaceae), Ixora sp. (Rubiaceae), Leea asiatica (L.) Ridsdale (Leeaceae), Lygodium flexuosum (L.) Sw. (Lygodiaceae), Pteris scabripes Wall. ex J. Agardh (Pteridaceae) and Selaginella sp. (Selaginellaceae). Flowers and fruits have been observed from August to September.

Conservation status. - Sonerila konkanensis is currently known only from one locality with two sub-populations in an unprotected area, separated by a distance of 200-300 m. A total of 90 mature individuals were found in an area of c. $4 \mathrm{~km}^{2}$. It is likely that more populations in similar habitats in the same hill are not yet known and further surveys are needed to determine the exact distribution range of this species. The type locality being a tourist destination, and considering the possibility of further ecological disturbances of this restricted range species, we provisionally assess the new species as "Vulnerable" [VU B1ab(iii)] according to IUCN Red List Categories and Criteria (2012).

Notes. - Sonerila konkanensis is a tuberous species with angular stems, lime green leaves, pale pink flowers and acuminate to rostrate anthers. Many other species of Sonerila in India also have angular stems and tuberous root stocks but none of them are morphologically closely related to the new taxon. Sonerila konkanensis and S. talbotii are recognised by their stems, branches, petioles, laminae, peduncles, pedicels and hypanthia all covered by dense glandular trichomes. The density of the glandular trichomes on the laminae in S. konkanensis is variable and the glandular heads dry up when old. Sonerila konkanensis also differs from S. talbotii and $S$. sreenarayaniana in having obovoid seeds without prominent raphe (vs. ellipsoid with prominent raphe) and 
the testa tubercles somewhat smooth (vs. covered with small pusticles). This species is further characterised by its large $(0.5-2.5 \times 0.5-1.5 \mathrm{~cm})$, leaf-like, persistent bracts, which are not reported in any other Sonerila species from India.

Additional specimens examined. - India. Goa: South Goa dist., Salcete taluk, Chandreshwar hills, Chandranath, 16.IX.1997, Joshi \& Rajkumar 962 (Goa University Herb.); near Bhoothnath temple, 9.IX.2007, fl. \& fr., Ashish 532 (Goa University Herb.); on the way to Chandreshwar temple, [15 $12^{\prime} 57^{\prime \prime} \mathrm{N}$ 74 02'12"E], 273 m, 3.IX.2019, fl. \& fr., Resmi छ Akshatra 164409 (CALI).

\section{Acknowledgements}

The authors are thankful to the Head of the Department of Botany of the University of Calicut for facilities; Ms. Rutuja R. Kolte (Research Scholar) for helping during the field trips and locating relevant sites; the curators of the herbaria CAL, CALI, MH, TBGT and Goa University Herbarium for permitting us to study the specimens. SN also thanks Science Engineering Research Board (SERB), New Delhi for funding (Sanction No: EMR/2016/007346, dated 29.10.2018). RS is grateful to the International Association for Plant taxonomy for the IAPT Research Grant 2020 and to the Government of Kerala for the fellowship granted. Finally, we thank two anonymous reviewers for their comments that improved an earlier version of this manuscript.

\section{References}

Cellinese, N. (1997). Notes on the systematic and biogeography of the Sonerila generic alliance (Melastomataceae) with special focus on fruit characters. Trop. Biodivers. 4: 83-93.

Chantaranothai, P. (1997). Palynological studies in the family Melastomataceae from Thailand. Grana 36: 146-159.

Clarke, C.B. (1879). Sonerila. In: Hooker, J.D. (ed.), Fl. Brit. India 2: $529-540$.

Cogniaux, A.C. (1891). Sonerila. In: Candolle, A. de \& C. DE Candolle (ed.), Monogr. Phan. 7: 490-516.

Giri, G.S. \& M.P. NAYAR (1986). A new species of Sonerila (Melastomataceae) from India. J. Jap. Bot. 61: 344-348.

IUCN (2012). IUCN Red List Categories and Criteria: Version 3.1. Ed. 2. IUCN Species Survival Commission, Gland and Cambridge.

Lundin, R. (1983). Taxonomy of Sonerila (Melastomataceae) in Ceylon. Nordic J. Bot. 3: 633-656.

Patel, V.C., J.J. Skvarla \& P.H. Raven (1984). Pollen characters in relation to the delimitation of Myrtales. Ann. Missouri Bot. Gard. 71: 858-969.
Resmi, S., K.M. Manudev, C. Pramod \& S. Nampy (2018). A new species of Sonerila (Melastomataceae: Sonerileae) from southern Western Ghats, India. Phytotaxa 333: 235-242. DOI: https://doi. org/10.11646/phytotaxa.333.2.7

Stapf, O. (1892). On the Sonerileae of Asia. Ann. Bot. (Oxford) 6: 291-323.

SteArn, W.T. (1992). Botanical Latin: history, grammar, syntax, terminology and vocabulary. Ed. 4. David \& Charles, London.

Sunil, C.N., V.V. Naveen Kumar \& T.S. Rajeev (2014). Sonerila sreenarayaniana (Melastomataceae), a new species from Kerala, India. Int. J. Adv. Res 2: 701-704.

Triana, J.J. (1871). Les Melastomacées. Trans. Linn. Soc. London 28: 1-188. 